Life lessons
$\begin{aligned} & \text { Court rules against } \\ & \text { anti-evolution } \\ & \text { stickers on textbooks } \\ & p 182\end{aligned}$

\title{
Titan team claims just deserts as probe hits moon of crème brîlée
}

Alison Abbott, Darmstadt

Scientists were ecstatic last weekend as Titan, Saturn's largest moon, dramatically revealed itself to have the atmosphere-bearing, hydrocarbon-based landscape they had anticipated.

But Huygens, the European Space Agency (ESA) spacecraft that successfully parachuted through Titan's atmosphere on 14 January, has also revealed its share of surprises. The high-risk mission had functioned better than its designers had dared to expect - and they quickly reported that the moon looked even more interesting than they had hoped.

The probe successfully transmitted data from its six instrument packages during a 2.5-hour descent through Titan's atmosphere, and for more than 70 minutes after it landed.

Scientists waiting anxiously for the data to arrive at the European Space Operations Centre (ESOC) in Darmstadt, Germany, hugged each other when the first signals arrived during the morning, showing that the mission, 20 years in the planning and execution, was functioning. Many had worked most of the previous night preparing for the data's arrival.

Their delight grew as theybegan to look at what the data - relayed in compressed form from the mother ship Cassini in the late afternoon - seemed to be telling them.

"My worst nightmare had been that Titan would turn out to be a bland object, a simple icy surface with no structure or variety," says John Zarnecki, principal investigator on the Surface Science Package at the Open University in Milton Keynes, UK. "But it is fascinating geologically - it has weather, a variegated surface with lots of features and it keeps alive the idea that it has lakes made of liquid organic material."

It was 15 hours from the start of the data dump to the press conference that brought the world the first images of Titan. And they were perhaps the most intense times in the professional lives of the six Huygens investigators

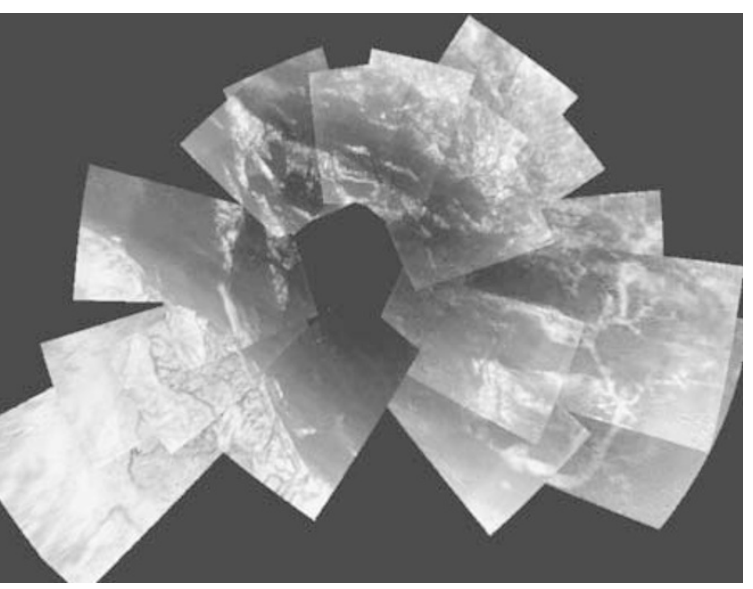

few centimetres from Titan's surface. Looking at the close-up photograph, experts at first thought they were seeing an old picture of Mars, with its flat, fog-free, boulder-filled landscape. "If this really were Titan, then we would be in big trouble," commented one NASA scientist at the banquet, confident that the files had been confused.

But later, as more information trickled through from the control room, the small scale of the picture was made clear. The boulders were actually just a few centimetres across, and possibly made of very hard ice. And spectroscopic results showed Titan's clouds to be high and their teams from institutes in France, Germany, Britain and the United States.

Celebration and concentrated work ran in parallel. High-ranking guests, including ministers and space-agency officials, banqueted in ESOC's main building as scientists devoured data in the building next door.

Aware of the pressing need to tell the world a story at short notice, yet knowing that the whole, nuanced tale would require years of data analysis, the teams sprang into action. They did quick scans of their entire data sets to see which individual instruments were delivering information that seemed to make immediate sense. Then all team members dived into analyses of these particular data to provide a taste of the stories to come.

\section{Public image}

"If we hadn't had a large public waiting for a story, we probably would not have worked this way," says Zarnecki. "We would have taken a more structured, disciplined approach, where team members would work through data from different parts of each experiment." But he adds that scientists "have changed over the past few years, and appreciate a duty to inform taxpayers of how their money is being spent".

Within a few hours of the landing, Marty Tomasko of the University of Arizona in Tucson had used data from his camera to select three pictures taken $16 \mathrm{~km}, 8 \mathrm{~km}$ and around $20 \mathrm{~km}$ up — making for a clear lower atmosphere.

The intensity of the work - and of the celebrations - continued through the night in the science rooms. Marcello Fulchignoni of the Paris-Meudon Observatory was hurriedly transforming his team's results on the physical and electrical properties of Titan's atmosphere into sound. "The transformation doesn't have any scientific value, but it fires the imagination of the general public," he says.

Around midnight, Fulchignoni dived out to pick up the bottles of champagne, specially labelled with the logo of his experiment, which he had laid down when Cassini-Huygens was launched in 1997. By 2:30 a.m. Zarnecki, whose team was sharing the same room, had opened the malt whisky that he had won on a sweepstake to guess the exact time of Huygen's landing. Sometime in those heady hours, Zarnecki coined a description of Titan's soft but crusted surface that looks likely to stick: crème brûlée.

By the time the world's press began pouring through the ESOC gates at 10 a.m., many bies. But the Huygens investigators managed to suppress their exhaustion and conduct interviews well into the early afternoon.

What happened next? A nap, perhaps? "Well, we worked a bit more in the afternoon, and then I took my team out for dinner in the evening," says Zarnecki. of the scientists were shuffling out like zom- 